Daniela Belmar Mac-Vicar, A nadie se culpe de mi muerte. Suicidios entre 1920-1940. Santiago y San Felipe

Ediciones Universidad Alberto Hurtado, Santiago, 2018, 243 p.

María José Correa Gómez

\title{
OpenEdition
}

Journals

Edición electrónica

URL: http://journals.openedition.org/rhj/3908

DOI: $10.4000 /$ rhj.3908

ISSN: 0719-4153

Editor

ACTO Editores Ltda

Referencia electrónica

María José Correa Gómez, «Daniela Belmar Mac-Vicar, A nadie se culpe de mi muerte. Suicidios entre

1920-1940. Santiago y San Felipe », Revista Historia y Justicia [En línea], 14 | 2020, Publicado el 27 julio 2020, consultado el 25 septiembre 2020. URL : http://journals.openedition.org/rhj/3908 ; DOI : https:// doi.org/10.4000/rhj.3908

Este documento fue generado automáticamente el 25 septiembre 2020

Revista Historia y Justicia 


\section{Daniela Belmar Mac-Vicar, A nadie se culpe de mi muerte. Suicidios entre 1920-1940. Santiago y San Felipe}

Ediciones Universidad Alberto Hurtado, Santiago, 2018, 243 p.

María José Correa Gómez

REFERENCIA

Daniela Belmar Mac-Vicar, A nadie se culpe de mi muerte. Suicidios entre 1920-1940.

Santiago y San Felipe, Ediciones Universidad Alberto Hurtado, Santiago, 2018, 243 p. 
"Por último, a nadie culpe, solo a mi melancolía que me ha muerto, joven, no fui grande pero muero tranquilo porque

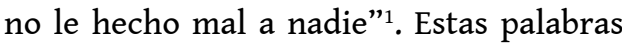
corresponden a las de Antonio Rosales, y fueron dejadas en la nota que acompañó su suicidio ocurrido en el Santiago de 1921. Como él, numerosos hombres y mujeres dejaron testimonios sobre sus muertes, sea a través de su palabra escrita o por medio de la palabra de otros que intentaron explicar sus acciones. Estas huellas constituyen registros sensibles del pasado, más allá de la conceptualización jurídica y legal de sus actos, que se vinculan con la pregunta principal que origina y guía este trabajo respecto a las motivaciones, explicaciones $y$ valorizaciones del suicidio en el chile de los años 20 y 30.

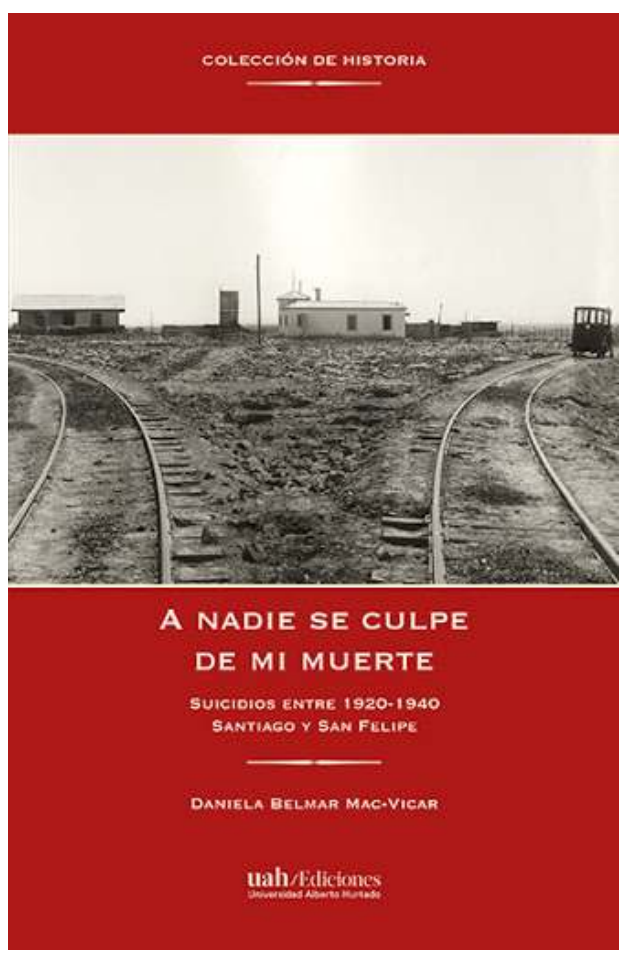

2 El libro de Daniela Belmar ofrece una entrada necesaria al tema del suicidio. Primero, por la reducida atención dada por la historiografía nacional a la llamada muerte voluntaria, pese a su diversificada presencia internacional. Esta solo ha alcanzado en los últimos años un mayor desarrollo en el país asociada a los trabajos de Mario Fabregat y de la misma autora del texto que revisamos ${ }^{2}$. Segundo, porque su aproximación no se queda solo en los aparatos jurídicos y médicos que han significado estas acciones, sino también aborda a sus protagonistas, los suicidas, en su círculo cercano y en las formas en que estos dialogaron con los saberes circulantes y narraron sus interpretaciones. Si bien una parte importante de su investigación revisa y problematiza el contexto que categorizó al suicidio particularmente ajustado al derecho y a la medicina -, el foco se aglutina en la atmósfera particular de aquellos que intentaron o lograron quitarse la vida.

Su trabajo, resultado de su investigación conducente al grado de Magíster en Historia de la Universidad de Chile, nos invita a pensar históricamente la práctica del suicidio con el objeto de reflexionar en torno a la construcción de sentido del acto de morir. La invitación es más que pertinente. El suicidio -sui (a sí mismo) y caedere (matar)- fue y continúa estando sumamente presente, no solo desde sus cifras, sino también desde los debates respecto al rol del Estado y la sociedad sobre un acto cuya interpretación ha transitado entre la decisión libre y voluntaria de terminar con la vida, y los contextos sociales y personales que determinan o regulan dichas acciones.

El libro constituye un aporte al estudio de la muerte y de su administración en el chile de la primera mitad del siglo XX, así como una entrada a la experiencia del morir y del derecho a ello, en tanto se enfoca en la muerte auto infringida y/o voluntaria y en los sentires que acompañaron su determinación y gestión. También corresponde a un cuidado trabajo sobre la justicia y el espacio gestado por los tribunales para la conceptualización lega y experta de este comportamiento, sus puntos de encuentro y distanciamiento. Por medio de una narración clara y bien documentada ofrece una 
lectura del suicidio y su experiencia en distintos niveles de la sociedad de las ciudades de Santiago y San Felipe, a través de la documentación judicial, lo que permite ponderar diferentes experiencias e interpretaciones de estos actos en la zona central del país.

La investigación en este sentido transita entre el estudio del suicidio como categoría y de los suicidios como experiencias individuales. Organizada en tres secciones, el libro entrega en su primer capítulo titulado Conceptos y enfoques un marco que permite leer históricamente, desde un tipo determinado de registros -textos legales, médicos, forenses y judiciales- la muerte auto-infringida, subrayando la importancia que ha tenido en su estudio, su conceptualización como situación límite anclada a un momento de crisis.

En su segundo capítulo titulado Contextos y prácticas implicadas, la autora ubica el problema en un periodo de agudización de las necesidades de la población. La cuestión social enmarca y potencia el trance que permite pensar en el fin de la vida; gesta y reproduce condiciones diferenciadas, difíciles, excesivas, que suman problemas a la existencia cotidiana y restan responsabilidad en la toma de las decisiones individuales. Como resultado, el suicidio aparece para muchos como una forma de violencia de aquella modernidad problemática que favorece vidas en las que no se garantizan las mínimas condiciones de subsistencia. En este contexto, el estudio agrega a dicho diagnóstico, conocido por la historiografía, la conceptualización médica y jurídica en torno al suicidio, con el objeto de analizar como "otros vieron y valoraron al suicida y al suicidio", particularmente desde la plataforma institucional. Así, los principales recursos de este capítulo están constituidos por tesis de derecho y medicina publicadas durante el periodo, así como textos judiciales y médico legales que se intersectaron de diversos modos con el suicidio, con su arribo a los tribunales y su relación con el saber forense. Por medio de estos registros, se reconoce el interés que profesionales y autoridades del derecho y la medicina comenzaron a mostrar respecto de este acto, y los cruces de género y de clase que enmarcaron sus interpretaciones. Así también aborda, las elaboraciones diseñadas desde la práctica pericial y sus especialistas, en el contexto de un proceso gradual de configuración de la medicina forense y de conformación de la institucionalidad médico legal asociada a la inauguración del edificio de Avenida La Paz. Se identifican interesantes entradas al problema, variedad en los registros usados, levantamiento de información relevante para la configuración del contexto, calibrada por la mirada experiencial que aportan los casos.

El tercer capítulo aborda las Motivaciones y atribuciones de responsabilidad del suicidio, que corresponden, como plantea la autora, a aquellos contextos específicos, sociales y subjetivos, en los que los suicidas estuvieron inmersos según los relatos de la justicia, y que pudieron haber incidido en sus actos. Las relaciones familiares y de pareja, los problemas económicos $\mathrm{y}$ las enfermedades fueron nombrados por los suicidas $\mathrm{y}$ utilizados para subrayar la autonomía de su proceder, presentando sus acciones como decisiones deliberadas tomadas en escenarios de complejidad. Es en este tercer capítulo donde se plasma el análisis más íntimo y privado relacionado con la vida de los suicidas y sus bemoles. Aquí se presenta a un grupo diverso que tiene como punto de encuentro las dificultades que le ofrece la vida. Pesares económicos, abandonos amorosos, compromisos fallidos, enfermedades dolorosas, senilidad, entre otros, acompañaron las percepciones de quienes optaron por terminar de vivir. También aparecen sus 
cercanos, quienes, con pesar, sorpresa, vergüenza, se acercan a la decisión tomada e intentan apoyar o elaborar una interpretación.

De este modo, a través de la palabra de los suicidas y la de sus cercanos la investigación indaga en la calificación del suicidio como muerte voluntaria y en las responsabilidades asociadas al acto de morir. Esto no resulta del todo inmediato en la medida que interactúan con sus consideraciones ideas médicas respecto a las enfermedades mentales que deconstruyen, en paralelo, el libre albedrío de sus acciones. Estos contenidos se apoyan en cuadros que aportan con datos cuantitativos que, si bien podrían considerarse poco representativos en general, arrojan resultados interesantes que la investigadora considera con cuidado y con matices, en el contexto de una investigación que apuesta por aspectos más cualitativos y subjetivos. Estos cuadros sugieren diversas preguntas, algunas no abordadas en el libro, que pueden transformarse en nuevos hilos de investigación, por ejemplo, en lo referente a aspectos etarios.

Interesante es también la consideración de las condiciones materiales del suicidio, en tanto acción que responde a las posibilidad y tecnologías del morir voluntario. El paso del tiempo enseña el desarrollo de nuevas prácticas de muerte, como lanzarse desde las alturas o ingerir productos manufacturados asociados al desarrollo de la construcción urbana en altura y al crecimiento del comercio y de la industria química y farmacéutica. El suicidio si bien no corresponde a un hecho de la modernidad, responde en sus características y significaciones a las nuevas condiciones que la metrópoli comenzó a vivenciar desde mediados del siglo XIX con el desarrollo fabril y la densificación poblacional. Investigaciones futuras podrían profundizar en estas condiciones, proyectándolas, además, desde el interés que la autora manifiesta por la problemática de la autonomía y del derecho a morir, acercándolas también a discusiones más contemporáneas relacionadas con la eutanasia. En esta dirección las tecnologías del morir son muy relevantes, no solo enmarcadas en el suicidio.

Uno de los temas centrales analizados en el libro corresponde al de la responsabilidad, pregunta que como bien señala Belmar, interesa profundamente a la justicia del periodo, por las vinculaciones criminales que podía esconder un acto como el suicidio. Este problema cruza un aspecto metodológico de la investigación, que se relaciona con el grupo estudiado, los suicidios judicializados. En este sentido, pese a que el suicidio, como bien se señala en el texto, no constituyó un delito, fue llevado a tribunales para verificar sus características y descartar un posible homicidio o la presencia de alguien que hubiese auxiliado o inducido este acto. Su judicialización, por tanto, es resultado de la necesidad de la justicia de despejar dudas respecto a las responsabilidades asociadas a esta muerte voluntaria. En este contexto, más allá de los intereses judiciales y retomando el interés por la agencia de los sujetos, sería interesante profundizar en la conformación del grupo de estudio, es decir, los suicidas judicializados, para revisar las tramas y causas que motivaron la existencia en tribunales de algunos y la ausencia de otros, principalmente en términos de clase y género. ¿Cómo se constituye la muestra? ¿Qué categorías se utilizan en la identificación de la documentación judicial? Estas cuestiones son necesarias de volver a abordar dado que, por las características del suicidio, este tendió a ser catalogado judicialmente, bajo diferentes etiquetas: como muerte accidental, encuentro de cuerpo, envenenamiento, entre otras. Ampliar esta mirada o circunscribir claramente el cuerpo de documentos bajo análisis, apoyará los resultados interpretativos de futuros trabajos. 
11 También, en términos de la historia del suicidio, sería enriquecedor profundizar en otras lecturas de la muerte voluntaria, como los suicidios heroicos o patrióticos en los que las explicaciones y argumentos esgrimidos ante tribunales no parecen tener mayor resonancia. Esto con el objeto de dialogar y tensionar los hallazgos e interpretaciones que ofrece el material judicial.

12 Finalmente, la lectura de expedientes permite poner atención a la historia narrada, atendiendo a las problemáticas centrales exhibidas por las personas en sus vidas $\mathrm{y}$, aun, en contextos especiales que determinaron los significados y experiencias de suicidio. En este sentido, la investigación opta, pensamos que acertadamente, por explorar e interpretar el suicidio, en tanto muerte voluntaria, de un modo que, como plantea Belmar, ya no remite a la descripción de un acontecimiento, sino, más bien "a un proceso de experiencia y narración social" que propone nuevas entradas interpretativas y cuya consideración, sin duda, enriquece una composición más rica de la historia de la vida y de la muerte en el pasado.

\section{NOTAS}

1. Archivo Nacional Histórico, Archivo Judicial de Santiago, Expediente no 13346, Suicidio de Antonio Rosales, 29 de junio de 1921, f.2, citado en Belmar, Daniela, A nadie se culpe de mi muerte. Suicidios entre 1920-1940. Santiago y San Felipe, Ediciones Universidad Alberto Hurtado, Santiago, 2018.

2. Entre los trabajos publicados de Fabregat, Mario, "La muerte bajo sospecha: procedimientos judiciales frente al suicidio, Chile, 1832-1920", Nuevo Mundo Mundos Nuevos, 2015 y Fabregat, Mario, "El suicidio: exégesis judicial, reconstrucción estadística y caracterización. Provincia de Santiago, 1900-1920", Revista Historia y Justicia, $\mathrm{n}^{\circ}$ 4, Santiago, abril 2015, p. 66-102.

\section{ÍNDICE}

Palabras claves: suicidio, muerte voluntaria, historia social, práctica pericial, siglo 20

Keywords: suicide, voluntary death, social history, expertise, 20th century

Mots-clés: suicide, mort volontaire, histoire sociale, expertise, 20e siècle 


\section{AUTORES}

\section{MARÍA JOSÉ CORREA GÓMEZ}

Universidad Nacional Andrés Bello (UNAB).

mariacorrea.mjc[at]googlemail.com 